\title{
AS RAZÕES DE DECIDIR DA ADPF 54 E SUAS IMPLICAÇÕES NOS CASOS DE MICROCEFALIA
}

\section{THE REASONS FOR DECIDING ADPF 54 AND ITS IMPLICATIONS IN CASES O MICROCEPHALY}

\section{Roberto Baptista Dias da Silva ${ }^{1}$ Thiago Melim Braga ${ }^{2}$}

RESUMO: O presente artigo tem por objetivo o estudo acerca da colisão entre o direito fundamental à liberdade de escolha e o direito à vida, partindo da análise de alguns conceitos de liberdade para, em seguida, ingressar na questão específica sobre o tema proposto, sendo adotadas, para tanto, duas abordagens metodológicas distintas: a primeira exploratória, justamente do enquadramento conceitual de cada um dos principais objetos que envolvem a questão analisada, por meio de uma pesquisa eminentemente bibliográfica; e a segunda, por sua vez, analítica, observando as razões adotadas pelo Supremo Tribunal Federal no julgamento da ADPF n. 54. O artigo pretende, também, fazer uma abordagem teórica sobre os aludidos tópicos e, ao final, verificar se há possibilidade de aplicação, devido aos inúmeros casos - a partir de 2015 - de transmissão do "Zika Vírus" no Brasil, das razões de decidir do julgamento da ADPF $n^{\circ} 54$ não só para os casos de anencefalia, mas também para os casos de microcefalia, este é o seu principal objetivo. Ao final, concluímos, com base no arcabouço metodológico, doutrinário e jurisprudencial adotados, que as razões de decidir da ADPF n ${ }^{\circ} 54$ não se aplicam aos casos de microcefalia.

Palavras-chave: Direitos fundamentais; Supremo Tribunal Federal; Anencefalia; Microcefalia; Razões de decidir.

ABSTRACT: The purpose of this article is to study the collision between the fundamental right to freedom choice and the right to life, starting with the analysis of some concepts of freedom and then entering the specific question on the proposed theme, therefore, two distinct methodological approaches were adopted: the first exploratory, precisely the conceptual framing of each of the main objects that involve the analyzed question, through an eminently bibliographical research; and the second,

\footnotetext{
${ }^{1}$ Doutor em Direito do Estado pela PUC-SP e professor de Direito Constitucional da PUC-SP e do curso de Administração Pública da FGV-SP (e-mail rdiasdasilva@pucsp.br). ORCID: https://orcid.org/0000-0002-2853-654X

2 Doutorando, mestre e especialista em Direito Constitucional pela PUC-SP (e-mail thiagomelimbraga@gmail.com). ORCID: https://orcid.org/0000-0003-0673-4067.
} 
in turn, analytical, checking the reasons adopted by Federal Supreme Court in the ADPF judgment $n$. 54. The article intends to take a theoretical approach on the aforementioned topics and, in the end, to verify if there is possibility of application, due to the numerous cases - from 2015 - of transmission of the "Zika Virus" in Brazil, of the reasons for deciding on the ADPF judgment 54 not only for cases of anencephaly, but also for cases of microcephaly, this is your main objective. In the end, we conclude, based on the methodological, doctrinal and jurisprudential framework adopted, that the reason for deciding ADPF $n^{\circ} 54$ do not apply to cases of microcephaly.

Key-words: Fundamental rights; Supreme Court; Anencephaly; Microcephaly; Reasons to decide.

Sumário: 1. Introdução; 2. Conceitos de Liberdade; 3. A diferença entre ratio decidendi e obiter dictum; 4. As razões de decidir na ADPF n. ${ }^{\circ}$ 54; 5 . Anencefalia e microcefalia; 6. As implicações das razões de decidir na ADPF 54 nos casos de microcefalia: análise conclusiva; 7. Referências.

\section{INTRODUÇÃO}

O Poder Judiciário tem sido, no Brasil, campo fértil para o debate e as proposições dos mais variados temas que importam às pessoas, especialmente no campo dos direitos fundamentais, como, de modo geral, o direito à liberdade e à vida e, mais especificamente, o direito ao aborto.

As reflexões expostas neste artigo nascem da correlação entre a possibilidade de aplicação das razões de decidir da ADPF n ${ }^{\circ} 54$ - que garantiu a o direito de as mulheres grávidas interromperem a gestação de feto anencéfalo - para os casos de microcefalia. O objetivo é justamente investigar a relação entre as razões de decidir da ADPF ${ }^{\circ} 54$ e os casos de microcefalia, que se espalharam pelo Brasil a partir de 2015.

Não pretendemos tratar, neste estudo, da ADPF 442, ajuizada pelo Partido Socialista Brasileiro - PSB em março de 2017, que busca a discriminalização do aborto até a $12^{\mathrm{a}}$ semana de gestação. $\mathrm{O}$ presente artigo se restringirá a discutir as razões de decidir da ADPF 54, que autorizou a interrupção da gravidez de feto anencéfalo, em confronto com o caso de microcefalia, pois, em ambos os casos, há o 
debate da interrupção da gravidez em razão de uma enfermidade do feto. Contudo, num caso - o da anencefalia -, há a confirmação médica da inviabilidade de vida extrauterina e, no outro - o da microcefalia -, isso não se dá. A questão que se coloca, então, é a seguinte: as razões de decidir na ADPF 54 devem se aplicar ao caso de interrupção da gravidez de feto infectado pelo vírus da Zika e diagnosticado com microcefalia?

A forma como, neste artigo, os temas propostos serão tratados seguiu duas abordagens metodológicas distintas. A primeira dessas abordagens consistiu numa análise exploratória do enquadramento conceitual de cada um dos principais objetos que envolvem a questão analisada, por meio de uma pesquisa eminentemente bibliográfica.

Esta metodologia foi complementada por uma segunda, analítica. A partir da bibliografia estudada, passamos a analisar as razões adotadas pelo Supremo Tribunal Federal no julgamento da ADPF 54, explorando o debate sobre o tema no âmbito do Judiciário.

Na primeira parte, analisaremos os conceitos de liberdade para, em seguida, darmos foco à distinção entre ratio decidendi e obiter dictum, a fim de, na terceira parte, a partir da análise do acórdão do Supremo Tribunal Federal na ADPF 54, investigar as razões de decidir nos casos de aborto decorrente da anencefalia no feto. $\mathrm{O}$ quarto item faz a distinção entre anencefalia e microcefalia e, para tanto, nos socorreremos de conceitos médicos. Por fim, a última parte do artigo se propõe a analisar se as razões de decidir na ADPF 54, em especial no campo do direito à liberdade, também poderiam ser aplicadas aos casos de microcefalia.

Ao final, formularemos nossas conclusões, reconhecendo a importância da análise da questão, notadamente pela relevância que tem na pauta do Supremo Tribunal Federal. 


\section{CONCEITOS DE LIBERDADE}

A relevância de tratarmos de um conceito geral de liberdade e sua positivação no ordenamento jurídico está relacionada à necessidade de estabelecermos premissas necessárias à compreensão do direito à liberdade frente ao direito à vida.

A distinção clássica entre liberdade negativa e liberdade positiva é bem traçada por Isaiah Berlin e Norberto Bobbio. ${ }^{3}$

Berlin (2002, p.229), para se aproximar desses dois conceitos, busca responder a duas questões. O sentido negativo de liberdade deve ser alcançado quando se responde à seguinte pergunta: "qual é a área em que uma pessoa ou um grupo tem permissão de fazer ou ser sem a interferência de outras pessoas?" No sentido positivo, a busca é pela resposta à seguinte questão: "o que ou quem é a fonte de controle ou interferência capaz de determinar que alguém faça ou seja uma coisa em vez de outra?"

Para Bobbio (1993, p. 97), por "liberdade negativa" deve-se entender "a situação na qual um sujeito tem a possibilidade de fazer ou de não fazer, sem ser obrigado a isso ou sem que o impeçam outros sujeitos". A liberdade negativa pressupõe, então, a ausência de impedimento, ou seja, a possibilidade de fazer. Mas também supõe a ausência de constrição, isto é, a possibilidade de não fazer (BOBBIO, 1993, p. 97). Por outro lado, a "liberdade positiva" é entendida como "a situação na qual um sujeito tem a possibilidade de orientar sua vontade para um objetivo, de tomar decisões, sem se ver determinado pela vontade dos outros" (BOBBIO, 1993, p. 100).

Nesse sentido, é possível perceber que, enquanto a liberdade negativa é uma qualificação da ação, a liberdade positiva é uma qualificação da vontade (BOBBIO, 1993, p. 102). E Bobbio (1993, p. 103-104) conclui que uma ação é livre, segundo a noção de "liberdade negativa", quando tal ação pode ser levada a cabo sem

\footnotetext{
${ }^{3}$ Este ponto é desenvolvido na seguinte obra: DIAS, 2012, p. 132 e ss.
} 
obstáculos, sem impedimentos. Já, conforme a ideia de "liberdade positiva", a vontade é livre se ela é autônoma, ou seja, quando a pessoa pode se autodeterminar.

As explicações de Bobbio acerca das duas noções de liberdade não diferem muito das de Berlin. Este último autor, ao tratar da liberdade negativa, afirma que "sou considerado livre na medida em que nenhum homem ou grupo de homens interfere com a minha atividade. A liberdade política nesse sentido é simplesmente a área na qual um homem pode agir sem ser obstruído por outros" (BERLIN, 2002, p. 229). Já o “sentido 'positivo’ da palavra 'liberdade’ provém do desejo que o indivíduo nutre de ser seu próprio senhor. Desejo que minha vida e minhas decisões dependam de mim mesmo, e não de forças externas de qualquer tipo. Desejo ser o instrumento de meus próprios atos de vontade, e não dos de outros homens. Desejo ser um sujeito, e não um objeto" (BERLIN, 2002, p. 246-247).

Com isso, é possível constatar que a "liberdade negativa" está comumente atrelada à ideia de direitos individuais, às chamadas liberdades civis. Seu sujeito histórico é o indivíduo. Ao passo que a "liberdade positiva", entendida como autodeterminação, como autonomia, se refere, geralmente, a um ente coletivo (BOBBIO, 1993, p.108). ${ }^{4}$

Apesar das diferenças, esses dois tipos de liberdade não são incompatíveis, visto que numa sociedade livre, como adverte Bobbio (1993, p. 104-105), a liberdade negativa dos indivíduos ou dos grupos é a condição para o exercício da liberdade positiva do conjunto. E, como ressalta Vieira (2017, p. 142-143), a Constituição brasileira de 1988 procura conciliar estas duas noções.

Ainda sobre o conceito de liberdade, interessa-nos a lição de Sarlet (2014, p. 446):

(...) o direito geral de liberdade atua como critério material para a identificação de outras posições jurídicas fundamentais, em especial, como

\footnotetext{
${ }^{4}$ BOBBIO, no entanto, deixa claro que essa dicotomia não é absoluta ao afirmar que o "impedimento (e não a constrição) e autodeterminação são, falando abstratamente, situações que podem estar ambas referidas tanto ao indivíduo singular como a um ente coletivo" (1993, p. 110).
} 
parâmetro para a dedução de liberdades específicas que não foram objeto de direta e expressa previsão pelo constituinte. Nessa perspectiva, o direito geral de liberdade pode ser interpretado em conjunto com o $\S 2^{\circ}$ do art. $5^{\circ}$ da CF, o qual estabelece um sistema aberto de direitos e garantias fundamentais, consagrando outros direitos não previstos de forma explícita no texto constitucional.

No intuito de reforçar esta linha argumentativa, a positivação de um direito geral de liberdade tem a vantagem de introduzir uma cláusula geral em nosso ordenamento. A introdução dessa cláusula permite que dela derivem outras liberdades que não são expressamente consagradas no texto constitucional, dentre elas a liberdade de escolha (autonomia da vontade) que, apesar de positivada por meio de interpretação extensiva de demais cláusulas constitucionais, pode ter sua margem de abrangência e efetividade ampliada.

A relação entre direito à liberdade, em especial do direito à liberdade de escolha, autonomia, guarda importante relevância com o tema aborto, enfoque central do presente artigo.

A liberdade deve ser entendida, ainda, como uma das condições essenciais à garantia da dignidade da pessoa humana. Nesse sentido, Martínez (1999, p. 215), em livre tradução, considera que "a liberdade é uma condição imprescindível para a ação, que permite alcançar a cada indivíduo os objetivos e fins morais que persegue e que são a expressão da dignidade humana, de sua consideração como fim em si, como algo valioso."

No Brasil, uma das concepções de Barroso sobre liberdade é a de que seja a garantia da dignidade da pessoa humana. Relacionando a autonomia com "as liberdades básicas (autonomia privada) e o direito à participação política (autonomia pública)" (2012, p. 82), argumenta que ela "é o elemento ético da dignidade humana" (2012, p. 81). Outrossim, a entende (BARROSO, 2012, p. 64):

Como um valor fundamental que é também um princípio constitucional, a dignidade humana funciona tanto como justificação moral quanto como fundamento jurídico-normativo dos direitos fundamentais. 
As definições de liberdade são inúmeras, como já constatava Montesquieu ${ }^{5}$ já evidenciamos acima. A corroborar esta afirmação, Luís Roberto Barroso (2001, p. 76) a concebe, por exemplo, como o "poder de autodeterminação, de deliberação sem interferências externas. Liberdade, assim, é ato de decisão e escolha entre vários possíveis". E também assim (BARROSO, 2001, p. 76-77):

A liberdade, efetivamente, tem um conteúdo nuclear que se situa no poder de decisão, de escolha, entre diversas possibilidades. Mas tais escolhas são condicionadas pelas circunstâncias naturais, psíquicas, culturais, econômicas e históricas. Portanto, trata-se de uma dimensão que não é apenas subjetiva, mas consiste na possibilidade objetiva de decidir.

Também podemos perceber que o conceito de liberdade não é estático. Para Martínez (1999, p. 216), por exemplo e em livre tradução, ele é polivalente, sendo capaz de elencar três categorias de liberdade, como a social, a política e jurídica e a psicológica e moral:

A liberdade como fundamento dos direitos humanos é consequência da existência de mecanismos de organização na vida social que permite ao homem buscar e, em seu caso alcançar, a autonomia, independência a liberdade moral, conseguir a comunicação que se dá através da linguagem e refletir sem impedimentos a construção de conceitos gerais.

As definições têm relevância em razão da relação do conceito de liberdade com o direito à vida, um dos pontos centrais deste trabalho. Demonstrada a relevância da abordagem preliminar acerca do conceito de liberdade e do direito geral de liberdade, Sarlet (2014, p. 450) sintetiza sua relevância da seguinte maneira:

Em síntese, o que importa para a apresentação do sistema das liberdades

\footnotetext{
${ }^{5}$ Para Montesquieu, "não existe palavra que tenha recebido tantos significados e tenha marcado os espíritos de tantas maneiras quanto a palavra liberdade" (MONTESQUIEU. 1993, p. 169). Sobre as controvérsias acerca do termo "liberdade", verificar Comparato (2006, p. 538 e ss.).
} 
fundamentais da Constituição Federal é que o direito geral de liberdade não esvazia, pelo contrário, reforça o conjunto dos direitos de liberdade em espécie, que representam direitos fundamentais autônomos com seu respectivo âmbito de proteção.

Assim, a ideia da qual partimos é a de reflexão sobre como o direito à liberdade, como a liberdade de escolha, a autonomia da vontade e os direitos reprodutivos da mulher, influem no direito ao aborto. Mas, antes de avançar neste ponto, passemos a analisar a diferença entre ratio decidendi e obiter dictum para, então, avançarmos na análise das razões de decidir da ADPF 54 e a possível influência delas para a análise do direito à interrupção da gravidez quando se constata a microcefalia do feto.

\section{A DIFERENÇA ENTRE RATIO DECIDENDI E OBITER DICTUM}

O texto de uma decisão judicial é a maior demonstração do raciocínio jurídico em operação, da aplicação do direito ao caso concreto. Um ato complexo, que deve relacionar uma cuidadosa análise do significado das disposições normativas abstratas e um exame das peculiaridades da situação real. O juiz não faz isso friamente, como um matemático que lida com fórmulas e equações. É preciso que ele expresse textualmente os passos deste percurso intelectual, formule um juízo racional. Para tanto, ele dispõe, sobretudo, de argumentos, sua grande ferramenta de trabalho.

Maximiliano (2017, p. 59) criou uma imagem ilustrativa para este ofício:

Existe entre o legislador e o juiz a mesma relação que entre o dramaturgo e o ator. Deve este atender às palavras da peça e inspirar-se no seu conteúdo; porém, se é verdadeiro artista, não se limita a uma reprodução pálida e servil: dá vida ao papel, encarna de modo particular a personagem, imprime um traço pessoal à representação, empresta às cenas um certo colorido, variações de matiz quase imperceptíveis; e de tudo faz ressaltarem aos olhos dos espectadores maravilhados belezas inesperadas, imprevistas. Assim o magistrado: não procede como insensível e frio aplicador mecânico de dispositivos; porém como órgão de aperfeiçoamento destes, intermediário entre a letra morta dos Códigos e a vida real, apto a plasmar, com a matéria-prima da lei, uma obra de 
elegância moral e útil à sociedade. Não o consideram autômato; e, sim, árbitro da adaptação dos textos às espécies ocorrentes, mediador esclarecido entre o direito individual e o social.

Várias modalidades de argumento podem ser encontradas no texto de uma decisão. Cada um tem peso relativo na composição do conjunto, da cadeia argumentativa. Nos sistemas jurídicos de common law, nos quais os julgados constituem precedentes que se aplicam a casos futuros, desenvolveu-se uma técnica especial de classificação dos argumentos judiciais. Como uma sentença é um texto discursivo, foi necessário criar um mecanismo conceitual que discernisse os argumentos que se generalizam daqueles circunstanciais, pertinentes somente ao caso concreto. A tentativa foi a de tornar o estudo dos precedentes uma atividade mais racional e controlável, uma técnica que disciplinasse o diálogo sobre a jurisprudência entre aplicadores do direito. Foi assim que lá se construiu a doutrina dos precedentes.

O juiz, no processo de solução do problema que lhe é posto, articula diversas espécies de razões. Cada uma destas razões desempenha um determinado papel, possui um certo grau de relevância no todo. Há aquelas fundamentais para a decisão. Outras cumprem papel subsidiário. Outras, ainda, puramente retóricas, absolutamente secundárias. Não se pode perder de vista, porém, seus valores argumentativo, simbólico e emocional.

Nos sistemas de common law criou-se um código para facilitar a identificação de tais razões. Existem razões que compõem a ratio decidendi (holding). Correspondem aos fundamentos definitivos para decidir, à prescrição que pode ser aplicada a casos futuros. Há um segundo grupo chamado de obiter dictum. Estes são os componentes marginais ao argumento geral, dizeres a propósito do caso concreto em si e que não lhe transcendem, nem alcançam os casos futuros. Localizam-se na periferia da decisão.

Logo, em qualquer julgado, temos a razão de decidir, sem a qual a decisão não se perfaz, e também argumentos periféricos que, extraídos do julgado, não lhe causam perda de sentido ou não possibilitam que sejam compreendidos de forma clara e 
objetiva. O objetivo, portanto, é extrairmos quais as razões de decidir da ADPF $n .^{\circ}$ 54 , sem as quais o julgamento não seria ultimado.

\section{AS RAZÕES DE DECIDIR NA ADPF 54}

Da análise e comparação dos votos, que realizaremos a seguir, será possível verificarmos que o Supremo Tribunal Federal decidiu, por maioria, pela atipicidade da conduta da mulher que interrompe a gravidez de feto anencéfalo. Isso por tomar como pressuposto de vida a potencialidade de vida extrauterina, a qual não é reconhecida ao feto anencéfalo, embora a existência de vida intrauterina não tenha sido resolvida pelo julgamento.

A definição biológica de vida não precisa, necessariamente, coincidir com seu conceito jurídico. O direito à vida não é absoluto e os direitos do nascituro são condicionados à possibilidade de vida extrauterina viável, potencialidade esta que é objeto de proteção da proibição do aborto. Desse modo, o Direito não tutelaria o feto anencéfalo.

O Supremo Tribunal Federal alude que, à época da promulgação do Código Penal, não existia tecnologia capaz de detectar previamente a anencefalia, razão que justifica o legislador não ter previsto a excludente do crime de aborto para o caso do anencéfalo. Além disso, constata que as excludentes já previstas no Código Penal aborto necessário e aborto humanitário - estariam a tutelar a saúde física e psíquica da mãe, respectivamente. A gravidez de feto anencéfalo gera maiores riscos físicos e psíquicos à gestante. Embora tenha considerado legítima a sua própria atuação ao decidir tal caso e tenha entendido pela procedência da ADPF, o Supremo faz a ressalva de que a sentença proferida não se estende a qualquer prática abortiva.

Há, contudo, que se ponderar que os conceitos adotados na decisão da Corte não foram totalmente claros ou bem delineados. É o que ocorre com os requisitos de "potencialidade" ou "viabilidade" de vida extrauterina para a tutela jurídica do feto. 
Não há qualquer explicação que conceitue esses pressupostos ou que justifique por que a ainda que curta vida do anencéfalo fora do útero não seja considerada viável. Seria pela falta de alguma capacidade específica? Pelo curto tempo vivido? Se sim, qual capacidade? Ou quanto tempo é suficiente para se adequar ao requisito?

São questões que os ministros não chegaram a analisar ou, se mencionaram, como a Ministra Rosa Weber que especificou a capacidade para o convívio social, o fizeram com conceitos abertos e indeterminados. Daí a atenção para estes termos que podem ser utilizados como fundamento para a prática de aborto em outras situações que a vida extrauterina do feto esteja, de algum modo, comprometida, a exemplo dos casos de microcefalia.

De modo semelhante, a lógica de que o legislador não quer punir o aborto em caso de gravidez que imponha risco à saúde física ou psíquica da mãe pode ser utilizada para outros casos em que estes bens da gestante estejam, de alguma forma, ameaçados. Essas considerações importam na verificação do que pode ser usado como precedente para casos futuros em que o Judiciário venha a ser questionado acerca de outras situações de aborto.

Assim, por exemplo, um caso de gravidez de feto portador de alguma outra afecção congênita letal terá mais chance de receber a autorização do juiz para a realização de aborto, o qual poderá utilizar-se dos mesmos fundamentos do Supremo Tribunal Federal, tais como a falta de potencialidade de vida extrauterina ou a infração à saúde física e psíquica da mãe, já que estes não foram claramente delimitados pelos ministros para o caso específico da anencefalia. Já uma gravidez de um feto saudável não teria o mesmo êxito, uma vez que a decisão do Supremo claramente não se pautou apenas pelos direitos de liberdade, autonomia e privacidade da mulher, ou pela tônica do aborto como questão de saúde pública.

Verifiquemos os votos dos ministros individualmente, na supracitada 
$\mathrm{ADPF}^{6}$,partindo do Ministro Marco Aurélio, relator do caso, e prosseguindo, por opção metodológica, de acordo com a cronologia de apresentação de cada voto, por cada um dos Ministros.

O Ministro Relator dividiu o voto em duas partes principais: na primeira parte, argumentou que entre os direitos sexuais e reprodutivos da gestante e o suposto direito à vida do feto anencéfalo, os primeiros prevalecem. Destacamos, inicialmente:

Não se coaduna com o princípio da proporcionalidade proteger apenas um dos seres da relação, privilegiar aquele que, no caso da anencefalia, não tem sequer expectativa de vida extrauterina, aniquilando, em contrapartida, os direitos da mulher, impingindo-lhe sacrifício desarrazoado. A imposição estatal da manutenção de gravidez cujo resultado final será irremediavelmente a morte do feto vai de encontro aos princípios basilares do sistema constitucional, mais precisamente à dignidade da pessoa humana, à liberdade, à autodeterminação, à saúde, ao direito de privacidade, ao reconhecimento pleno dos direitos sexuais e reprodutivos de milhares de mulheres. $\mathrm{O}$ ato de obrigar a mulher a manter a gestação, colocando-a em uma espécie de cárcere privado em seu próprio corpo, desprovida do mínimo essencial de autodeterminação e liberdade, assemelha-se à tortura [109] ou a um sacrifício que não pode ser pedido a qualquer pessoa ou dela exigido (BRASIL, 2013, p. 68).

\footnotetext{
${ }^{6}$ Ementa: ESTADO - LAICIDADE. O Brasil é uma república laica, surgindo absolutamente neutro quanto às religiões. Considerações. FETO ANENCÉFALO - INTERRUPÇÃO DA GRAVIDEZ MULHER - LIBERDADE SEXUAL E REPRODUTIVA - SAÚDE - DIGNIDADE AUTODETERMINAÇÃO - DIREITOS FUNDAMENTAIS - CRIME - INEXISTÊNCIA. Mostrase inconstitucional interpretação de a interrupção da gravidez de feto anencéfalo ser conduta tipificada nos artigos 124, 126 e 128, incisos I e II, do Código Penal. Decisão: Após o voto do Senhor Ministro Marco Aurélio (Relator), que julgava procedente o pedido para declarar a inconstitucionalidade da interpretação segundo a qual a interrupção da gravidez de feto anencéfalo é conduta tipificada nos artigos 124, 126, 128, incisos I e II, todos do Código Penal, no que foi acompanhado pelos Senhores Ministros Rosa Weber, Joaquim Barbosa, Luiz Fux e Cármen Lúcia, e o voto do Senhor Ministro Ricardo Lewandowski, que julgava improcedente o pedido, o julgamento foi suspenso. Impedido o Senhor Ministro Dias Toffoli. Falaram, pela requerente, o Dr. Luís Roberto Barroso e, pelo Ministério Público Federal, o Procurador-Geral da República, Dr. Roberto Monteiro Gurgel Santos. Plenário, 11.04.2012. O Tribunal, por maioria e nos termos do voto do Relator, julgou procedente a ação para declarar a inconstitucionalidade da interpretação segundo a qual a interrupção da gravidez de feto anencéfalo é conduta tipificada nos artigos 124, 126, 128, incisos I e II, todos do Código Penal, contra os votos dos Senhores Ministros Gilmar Mendes e Celso de Mello que, julgando-a procedente, acrescentavam condições de diagnóstico de anencefalia especifica das pelo Ministro Celso de Mello; e contra os votos dos Senhores Ministros Ricardo Lewandowski e Cezar Peluso (Presidente), que a julgavam improcedente. Ausentes, justificadamente, os Senhores Ministros Joaquim Barbosa e Dias Toffoli. Plenário, 12.04.2012
} 
Na segunda parte do voto, o Ministro Marco Aurélio ainda tratou de uma interpretação evolutiva do Código Penal para justificar que o legislador só não previu a atipicidade da interrupção do feto anencéfalo porque à época não havia tecnologia para identificar a doença, mas se pode presumir que o legislador excluiria, tendo em vista inclusive a excludente do aborto de feto fruto de estupro, que é viável, e do feto que esteja pondo em risco a saúde da mãe.

A análise da Ministra Rosa Weber foi estruturada na atipicidade do fato, uma vez que não considerou haver vida no feto anencéfalo por não possuir atividade cerebral, tampouco capacidade para o que denominou de convívio social. Considerou, ademais, que a vida não é um valor absoluto no ordenamento jurídico e que, para o direito penal, há uma gradação em importância da vida protegida como bem jurídico conforme ocorre o desenvolvimento, mas que, no caso concreto analisado, havia dúvida sobre a aplicação da proteção à vida do feto, enquanto não restou dúvida sobre os direitos fundamentais da gestante envolvidos, de modo a prevalecer a preservação da autonomia, da dignidade, da liberdade reprodutiva e do direito de escolha da gestante. Devemos nos atentar e, portanto, destacamos:

Para concluir, ao enfoque da teoria da proporcionalidade, o quociente da divisão das razões em favor da liberdade da mulher em cotejo com a proteção do feto anencefálico por meio da omissão do Estado e da declaração de inconstitucionalidade da leitura que inclui a interrupção, ou a antecipação terapêutica do parto, em caso de comprovada anencefalia, presentes as certezas empíricas sobre a afetação da esfera de atuação de cada um dos princípios em jogo, é maior que um. Há, portanto, de ser preservada a liberdade da grávida, quando se vê diante de tão doloroso dilema, de optar sobre o futuro da sua gestação de feto anencéfalo.

O Ministro Joaquim Barbosa defendeu a atipicidade do fato por considerar que não há vida viável no feto anencéfalo, pugnando pela tutela da vida humana, que, em seu sentir, experimentaria graus diferenciados e que o Direito Penal protegeria apenas a hipótese em que o feto está biológica e juridicamente vivo. Restou consignado, ainda, o fato de o aborto de anencéfalo não ser considerado explicitamente lícito em 
razão da data da promulgação do Código Penal, em 1940, quando não havia tecnologia médica apta a diagnosticar, com certeza, a inviabilidade do desenvolvimento do nascituro pós-parto. Por fim, afirmou o Ministro que seria um contrassenso chancelar a liberdade e a autonomia privada da mulher no caso do aborto sentimental, em que o bem jurídico tutelado é a liberdade sexual da mulher, e vedar o direito a essa liberdade nos casos de má-formação fetal gravíssima, como a anencefalia, em que não existe um real conflito entre bens jurídicos detentores de idêntico grau de proteção jurídica. Destacamos dois pontos do voto do Ministro, respectivamente:

Veja-se: a lei não determina que nesse ou naquele caso o aborto deva necessariamente ocorrer. A norma penal chancela a liberdade da mulher de optar pela continuidade ou pela interrupção da gestação. E, neste caso, não incrimina sua conduta.

Em se tratando de feto com vida extrauterina inviável, a questão que se coloca é: não há possibilidade alguma de que esse feto venha a sobreviver fora do útero materno, pois, qualquer que seja o momento do parto ou a qualquer momento em que se interrompa a gestação, o resultado será invariavelmente o mesmo: a morte do feto ou do bebê. [...]

Seria um contrassenso chancelar a liberdade e a autonomia privada da mulher no caso do aborto sentimental, permitido nos casos de gravidez resultante de estupro, em que o bem jurídico tutelado é a liberdade sexual da mulher, e vedar o direito a essa liberdade nos casos de malformação fetal gravíssima, como a anencefalia, em que não existe um real conflito entre bens jurídicos detentores de idêntico grau de proteção jurídica. Há, na verdade, a legítima pretensão da mulher em ver respeitada sua vontade de dar prosseguimento à gestação ou de interrompê-la, cabendo ao direito permitir essa escolha, respeitando o princípio da liberdade, da intimidade e da autonomia privada da mulher (BRASIL, 2013, pp. 149-150).

De outro lado, foi defendido pelo Ministro Luiz Fux a construção jurisprudencial de uma nova hipótese de estado de necessidade supralegal para os casos de interrupção da gestação de fetos anencefálicos. Para ele, o fato de o legislador ter previsto a permissão do aborto sentimental seria a prova de que, caso o diagnóstico de anencefalia durante a gestação fosse possível à época da promulgação do Código Penal, teria ele previsto também essa hipótese de permissão do aborto, sob pena de incidir em grave desproporcionalidade. No caso, a criminalização do aborto 
de feto anencéfalo agravaria ainda mais os custos sociais do infortúnio, de modo que a questão deveria ser tratada como matéria de saúde pública segundo uma política de assistência social eficiente. A questão mais relevante abordada em seu voto, além da hipótese de estado de necessidade supralegal, evidencia-se, ao nosso sentir, na análise a partir de um viés de saúde e política pública, senão vejamos:

Revela-se inequívoco, assim, que a interrupção da gravidez de fetos anencefálicos é matéria de saúde pública, que aflige, em sua maioria, as mulheres - como disse o Ministro Marco Aurélio - que compõem a parcela menos abastada da população. A questão deve ser tratada como uma política de assistência social eficiente, que dê à gestante todo o apoio necessário em uma situação tão lastimável, e não uma repressão criminal, uma repressão penal destituída de qualquer fundamento razoável (BRASIL, 2013, p. 170).

A Ministra Cármen Lúcia, ao antecipar seu voto, também no sentido da procedência da ADPF 54, destacou alguns dos aspectos mais relevantes em relação ao caso, como o direito à saúde, o direto à vida e toda a questão emocional e psicológica a que é submetida a gestante. Ressaltou a necessidade de se fazer um juízo de ponderação entre os princípios envolvidos para análise do presente caso e concluiu pela não criminalização dessa hipótese de interrupção da gravidez.

Da análise do voto do Ministro Ricardo Lewandowski - que decidiu pela improcedência da ADPF -, percebe-se como razões de decidir que a Corte Constitucional brasileira não poderia utilizar-se da técnica da interpretação conforme a Constituição no caso, uma vez que impedido pela univocidade das palavras e da vontade, explícita e deliberada, do legislador em não afastar a punibilidade da interrupção da gravidez de feto anencéfalo. Para o Ministro, haveria extrapolação das competências do Congresso, quando ao Supremo Tribunal Federal é dado apenas atuar como legislador negativo. Cumpre-nos destacar o que foi exposto neste sentido no acórdão:

Não se olvide, de resto, que existem vários diplomas infraconstitucionais 
em vigor no País que resguardam a vida intrauterina, com destaque para o Código Civil, o qual, em seu art. $2^{\circ}$, estabelece que "a lei põe a salvo, desde a concepção, os direitos do nascituro". Ou seja, mesmo que se liberasse genericamente o aborto de fetos anencéfalos, por meio de uma decisão prolatada nesta ADPF, ainda assim remanesceriam hígidos outros textos normativos que defendem os nascituros, os quais, por coerência, também teriam de ser havidos como inconstitucionais, quiçá mediante a técnica do arrastamento, ou, então, merecer uma interpretação conforme a Constituição, de modo evitar lacunas no ordenamento jurídico no tocante à proteção legal de fetos que possam vir a ter sua existência abreviada em virtude de portarem alguma patologia (BRASIL, 2013, p. 248).

Por sua vez, o Ministro Ayres Britto dividiu seu voto em duas partes: na primeira, rebateu os argumentos do Ministro Lewandowski para dizer que o conjunto normativo em questão (artigos do Código Penal referentes ao aborto) comportaria uma interpretação conforme a Constituição por ser polissêmico e haver controvérsia jurídica e social a ser dirimida; para comprovar, relatou a existência de três possibilidades de interpretação quanto ao alcance da norma penal relativamente ao feto anencéfalo: (i) a antecipação terapêutica do parto em caso de feto anencéfalo é crime; (ii) é fato atípico, pois não há vida em potencial; e (iii) é fato típico, mas não é punível, por prevalência, no caso, dos direitos da mulher (saúde física e psíquica, dignidade humana e liberdade de escolha).

A segunda parte do voto foi reservada a demonstrar a correção da segunda corrente, ou seja, da atipicidade, por considerar que não há vida em potencial no feto anencéfalo. Para além da discussão preliminar entre os Ministros, fato um tanto quanto comum na realidade da Corte, evidenciamos o seguinte excerto extraído dos autos:

É o reconhecimento desse direito que tem a mulher de se rebelar contra uma gravidez, um tipo de gravidez tão anômala que corresponde a um desvario da própria natureza - porque a natureza também se destrambelha, já dizia Tobias Barreto. É um direito que tem a mulher de interromper uma gravidez que trai até mesmo a ideia-força que exprime a locução "dar à luz". "Dar à luz" é dar a vida; não é dar a morte. É como se fosse uma gravidez, metaforicamente, que impedisse o rio de ser corrente; o rio salta da nascente para a embocadura. E é o que sucede, sem fluir, sem a ventura de se assumir também como 
corrente porque o rio é um rio só, da nascente à foz, passando pela corrente. E, no caso da gravidez de que estamos a falar, a fase corrente do rio é totalmente eliminada. A mulher já sabe por antecipação que o produto da sua gravidez, longe de, pelo parto, cair nos braços aconchegantes da vida, vai se precipitar - digamos assim - no mais terrível dos colapsos. É o colapso da luz da vida. O feto anencéfalo não passa de um organismo prometido à inscrição do seu nome não no registro civil, mas numa lápide mortuária (BRASIL, 2013, pp. 264265).

O Ministro Gilmar Mendes considerou o fato típico, uma vez que o feto anencéfalo pode nascer com vida e o desenvolvimento da vida passa necessariamente pelo estágio fetal, sendo, portanto, tutelado pelo direito, advertindo que sua análise seria de excludente de antijuridicidade, uma vez que interpreta ser essa a decisão extraída da própria opção do legislador que, ao excepcionar as hipóteses de aborto necessário e aborto humanitário, expressou os valores e bens jurídicos protegidos saúde física e psíquica da mãe -, justamente os bens ameaçados na gravidez de feto portador de anencefalia. Reconheceu, ao final, a legitimidade da Corte para proferir decisões manipulativas de efeitos aditivos, atuando como verdadeiro "legislador positivo", ainda que no âmbito penal, pois in bonam partem:

Entrementes, o aborto do feto anencéfalo tem por objetivo precípuo zelar pela saúde psíquica da gestante, uma vez que, desde o diagnóstico da anomalia (que pode ocorrer a partir do terceiro mês de gestação) até o parto, a mulher conviverá com o sofrimento de carregar consigo um feto que não conseguirá sobreviver, segundo a medicina afirma com elevadíssimo grau de certeza. Essa hipótese assemelha-se, em sua estrutura lógico-funcional, ao aborto de feto resultante de estupro, em que a principal intenção da norma é também a proteção da saúde psíquica da gestante, com a relevante distinção de que, neste último caso, permite-se a prática do aborto ainda que o feto seja saudável. A interpretação evolutiva sugerida pela inicial, destarte, demanda exegese construtiva do Tribunal, ante o surgimento de novo contexto fático-jurídico, bastante distinto daquele em que se deu a edição da parte especial do Código Penal brasileiro.

O Ministro Celso de Mello, por seu turno, defendeu duas posições: a primeira, e principal, ao nosso sentir, consistiu-se na defesa da atipicidade do fato, pois, não havendo atividade cerebral no feto anencéfalo, não há que se falar em vida; e se não 
há vida a ser protegida, nada justifica a restrição aos direitos fundamentais da gestante. Ainda nessa seara, entendeu que se houvesse o arsenal de conhecimento tecnológico de hoje, provavelmente, o legislador teria permitido, além das duas excludentes já existentes, o anencefálico, diante da absoluta certeza de inexistência de vida:

A separação constitucional entre Estado e Igreja, desse modo, além de impedir que o Poder Público tenha preferência ou guarde hostilidade em relação a qualquer denominação religiosa, objetiva resguardar duas (2) posições que se revestem de absoluta importância: (1) assegurar, de um lado, aos cidadãos, a liberdade religiosa e a prática de seu exercício, e (2) obstar, de outro, que grupos fundamentalistas se apropriem do aparelho de Estado, para, com apoio em convicções ou em razões de ordem confessional, impor, aos demais cidadãos, a observância de princípios teológicos e de diretrizes religiosas (BRASIL, 2013, p. 338). ${ }^{7}$

Em relação à segunda posição, asseverou o Ministro que mesmo que se considerasse o fato típico, tratar-se-ia de hipótese configuradora de causa supralegal de culpabilidade por inexigibilidade de conduta diversa, uma vez que inexistente em tal contexto "motivo racional, justo e legítimo, que possa obrigar a mulher a prolongar inutilmente a gestação e a se expor a desnecessário de sofrimento físico e/ou psíquico com grave dano à sua saúde e com possibilidade até mesmo de risco de morte" (BRASIL, 2013, p. 358). Desse modo, a incidência da norma penal relativa ao crime de aborto seria desproporcional e inconstitucional.

O outro voto pela improcedência ficou a cargo do Ministro Cezar Peluso, argumentando que há vida no feto anencéfalo, pois dotado da capacidade de movimento autógeno vinculado a um processo contínuo de evolução do ser. A vida humana, segundo seu voto, merece valor supremo, assegurado pela ordem constitucional, sobrepondo-se a qualquer outro bem jurídico e não podendo, fora das previsões legais específicas, ser relativizada. Outrossim, apontou para dificuldade de se apurar com certeza se se trata de diagnóstico de anencefalia fetal ou outra anomalia

${ }^{7}$ Destacado no original. 
semelhante distinta apenas em grau, de modo que não é razoável decidir de acordo com esta difícil distinção de conceitos de anomalias quem merece viver ou não; e, ao final, afastou o argumento de sofrimento psíquico, pois o sofrimento em si não degradaria a dignidade humana, seria elemento inerente ao homem, bem como os direitos à autonomia da vontade e liberdade de escolha da mulher, pois estes se preordenam para o cometimento de crime claramente punido pelo ordenamento jurídico. Também argumentou o Ministro que os meios científicos de diagnóstico de anencefalia estão disponíveis antes da reforma penal de 1984 de modo que, se fosse de sua vontade, o legislador teria aberto nova excludente. Nesse sentido:

A solução não cabe nesta via, em primeiro lugar diante da reconhecida impossibilidade de aplicação analógica ou interpretação expansiva de normas limitadoras de excludentes de punibilidade, em restrição ou dano ao alcance da tutela constitucional garantida à dignidade da vida humana. Nesta seara, a interpretação há de ser, antes, ampla e generosa na proteção ao valor supremo do ordenamento jurídico, sobretudo quando, como no caso, eventual mutilação hermenêutica do espectro dessa tutela seria sustentada e imposta para favorecer mero sentimento doloroso doutros seres humanos, como se tal estado psíquico, a que estão sujeitas todas as pessoas, constituísse título jurídico hábil para, sob fundamento de excessiva insuportabilidade, justificar o extermínio da vida de inocentes indefesos.

Não se pode tampouco, em segundo lugar, pedir a esta Corte que, atuando indevidamente como legislador positivo, tenha a ousadia de criar hipótese de exclusão de punibilidade do aborto, ou de desnaturar-lhe a tipicidade, quando carece de legitimidade e competência constitucionais para tanto (BRASIL, 2013, p. 412).

A decisão, enfim, se deu por 8 votos a 2. Acompanharam o voto do Ministro Relator Marco Aurélio os Ministros Joaquim Barbosa, Rosa Weber, Luiz Fux, Cármen Lúcia, Ayres Britto, Gilmar Mendes e Celso de Mello, e ficaram vencidos os Ministros Ricardo Lewandowski e Cezar Peluso. O Ministro Dias Toffoli não votou, pois se declarou impedido. Passemos, agora, à diferença conceitual entre anencefalia e microcefalia.

Apesar da dificuldade de sistematizar quais são os argumentos que levaram a Corte Constitucional brasileira a julgar procedente ou improcedente uma ação - 
especialmente em razão da forma como a decisão é proferida, com os Ministros proferindo seus votos isoladamente e que, muitas vezes, não dialogam -, faremos o esforço de identificar quais foram as razões de decidir no caso da ADPF 54. Em síntese, podemos dizer que a maioria dos Ministros entendeu que é atípico o fato de se interromper a gravidez de feto anencéfalos, pois, sem atividade cerebral, não há que se falar em vida. A segunda razão é que não devemos exigir da mulher o prolongamento inútil da gestação, expondo-a a desnecessário de sofrimento físico e/ou psíquico com grave dano à sua saúde. Impor a gravidez, na hipótese de anencefalia, contraria os princípios da dignidade da pessoa humana, liberdade, autodeterminação, saúde, privacidade e ao pleno reconhecimento dos direitos sexuais e reprodutivos de milhares de mulheres.

\section{ANENCEFALIA E MICROCEFALIA}

Behrman, Kliegman e Jenson (2002, p. 1777) definem, do ponto de vista médico, a anencefalia:

Anencefalia é definida como a má-formação fetal congênita por defeito do fechamento do tubo neural durante a gestação, de modo que o feto não apresenta os hemisférios cerebrais e o córtex, havendo apenas resíduo do tronco encefálico.

Por sua vez, a microcefalia, segundo a Organização Mundial da Saúde (2019, $\mathrm{s} / \mathrm{p}$ ), é descrita da seguinte forma:

A microcefalia é uma condição em que o bebê tem um tamanho de cabeça muito menor em comparação com outros bebês da mesma idade e sexo. $\mathrm{O}$ tamanho da cabeça é um indicador importante para monitorar o crescimento do cérebro da criança. A gravidade da microcefalia varia de leve a grave. Microcefalia pode estar presente quando do nascimento 
(congênita) ou pode se desenvolver no pós-natal (adquirida). ${ }^{8}$

A epidemia de Zika renovou as discussões sobre o direito ao aborto no Brasil. O debate atual é similar às discussões sobre rubéola que ocorreram em vários países em meados do século XX. No Brasil, contudo, esse debate nunca ocorreu. Na época, o aborto não era objeto de debate público e esse silêncio permaneceria até o fim dos anos 1970. Ainda assim, existe um caso nacional que é de interesse ao debate atual e ele diz respeito ao HIV.

Quando a epidemia de AIDS teve início, muitos países desenvolvidos já tinham legalizado o aborto. No Brasil, entretanto, o aborto era, e segue sendo, em grande medida ilegal ${ }^{9}$. No início dos anos 1990, o número crescente de mulheres soropositivas, aliado à falta de tratamento efetivo para a AIDS, levou à discussão sobre se essas mulheres deveriam ter o direito à interrupção da gravidez. Essa exceção nunca foi adicionada à legislação e o posterior desenvolvimento de tratamentos que não apenas tornaram a AIDS administrável, mas também reduziram o risco de transmissão vertical, esvaziou a discussão. De todo modo, ao contrastarmos as duas discussões, podemos compreender melhor os percursos do debate sobre aborto no Brasil e melhor nos posicionar nesse debate.

A principal diferença digna de destaque entre os dois debates diz respeito aos atores que o protagonizaram no Congresso Nacional. No início dos anos 1990, todos os três projetos de lei que discutiam HIV e aborto visavam a expandir o direito ao aborto no Brasil. Dois - PL 2.023/1991 e PL 3.005/1992 - buscavam exclusivamente tornar o aborto legal para mulheres soropositivas, enquanto o terceiro - PL 1.174/1991 - procurava tornar o aborto legal em casos de "enfermidade grave e

\footnotetext{
${ }^{8}$ No original: "Microcephaly is a condition where a baby has a head size much smaller compared with other babies of the same age and sex. Head size is an important measurement to monitor a child's brain growth. The severity of microcephaly ranges from mild to severe. Microcephaly can be present at birth (congenital) or may develop postnatally (acquired).

${ }^{9}$ Como já mencionado neste artigo, o aborto, com base no Código Penal de 1940 e após o julgamento da ADPF 54, pode ser provocado licitamente nas seguintes hipóteses: risco de vida para a gestante, gravidez decorrente de estupro e gestação de feto anencéfalo.
} 
hereditária" do nascituro, entre os quais os autores incluíam a AIDS. Já em 2016, o único projeto de lei que diz respeito a aborto e Zika - PL 4.396/2016 - visava a aumentar a pena "quando o aborto for cometido em razão da microcefalia ou qualquer outra anomalia do feto".

Por sua vez, outra questão para observarmos é a relacionada ao alcance do debate público. Buscas em ferramentas de busca da internet - como o Google, por exemplo - identificam vários artigos sobre aborto e Zika em todos os principais veículos de notícias do país, bem como em várias publicações internacionais. Fica claro que um número muito maior de pessoas está agora prestando atenção no tema, diferentemente do que ocorria no início da década de 90 com o HIV.

O aborto tornou-se objeto de discussões mais amplas como resultado das ações de grupos conservadores. Parlamentares conservadores, especialmente os ligados às igrejas evangélicas e católica, têm tornado o aborto cada vez mais um foco de suas campanhas e atuação legislativa.

Pesquisa feita pelo Datafolha em agosto de 2018 mostrou que a maioria dos brasileiros seguia contrária a mudanças na legislação sobre aborto no país. Mas o apoio à manutenção das regras atuais caiu de 67\% em novembro de 2015 para 59\% em agosto de 2018 . No mesmo período, também caiu de $16 \%$ para $13 \%$ a parcela da população que defende a ampliação das hipóteses de legalização do aborto. Contudo, os que defendem a legalização do aborto em qualquer situação aumento de $11 \%$ para $14 \%{ }^{10}$. Em fevereiro de 2016, no auge da epidemia de Zika no Brasil, o mesmo instituto de pesquisa detectou que a maioria da população brasileira (58\%) se opõe ao direito ao aborto mesmo em casos de microcefalia ${ }^{11}$. Como mudar essa realidade é

${ }^{10}$ Maioria dos brasileiros segue contrária à legalização do aborto, mostra Datafolha. Folha de S. Paulo. 22 ago. 2018. Disponível em https://www1.folha.uol.com.br/cotidiano/2018/08/maioriados-brasileiros-segue-contraria-a-legalizacao-do-aborto-mostradatafolha.shtml?loggedpaywall?loggedpaywall. Acesso em 23 jun. 2019.

${ }^{11}$ FERRAZ, L. Maioria dos brasileiros desaprova aborto mesmo com microcefalia. Folha de S. Paulo. 29 fev. 2016. Disponível em http://www1.folha.uol.com.br/cotidiano/2016/02/1744476maioria-dos-brasileiros-desaprova-aborto-mesmo-com-microcefalia.shtml. Acesso em 23 jun. 2019. 
algo que ativistas pró-direito ao aborto vêm enfrentando por muitos anos. E as dificuldades devem aumentar, dado que um Congresso Nacional cada vez mais conservador arrisca fechar as portas até das áreas do governo que anteriormente se mostraram receptivas à legalização do aborto.

A última grande diferença entre os dois debates é a questão da judicialização. No seu livro sobre direitos reprodutivos no Brasil, Ventura (2009) afirma não ter encontrado nenhuma decisão judicial relacionada à AIDS e à saúde reprodutiva. Essa ausência de decisões contrasta com o número crescente de mulheres que buscaram os tribunais para interromper legalmente gravidezes de fetos anencéfalos a partir dos anos 2000. Isso levou, em 2004, à Ação de Descumprimento de Preceito Fundamental (ADPF) 54 e permitiu o debate acerca de outras realidades para o caso brasileiro.

Essa tendência em direção à judicialização também está presente no caso da Zika. A ANADEP - Associação Nacional dos Defensores Públicos, em agosto de 2016, propôs perante o STF a Ação Direita de Inconstitucionalidade 5581, que, entre outros pontos, sustenta a viabilidade da interrupção da gravidez no caso de diagnóstico e infecção pelo vírus Zika, pois a mulher estaria em estado de necessidade. Além disso, citando a decisão na ADPF 54, a ANADEP argumenta, na inicial da referida ADI, que a autorização para o aborto também estaria fundada no fato de o direito à vida não ser absoluto e, em colisão com a vida do feto, deveria prevalecer o direito à vida digna da mulher, bem como o direito à autodeterminação sexual e à autonomia reprodutiva, podendo e grávida escolher não continuar com a gravidez que lhe causa grande sofrimento. A inicial sustenta também que a saúde mental da mulher grávida está em jogo no caso de infecção pelo vírus Zika.

A Procuradoria-Geral da República, sobre este ponto, manifestou-se pelo acolhimento do pedido inicial sob o argumento de que exigir a continuidade forçada da gestação, quando há a constatação da infecção pelo vírus Zika, abala a saúde psíquica da mulher. Ocorreria, no caso, "violação do direito fundamental à saúde mental e à garantia constitucional de vida livre de tortura e agravos severos", como, 
aliás, já reconheceu o STF na ADPF 54.

A decisão anterior, proferida na ADPF 54, não é garantia de sucesso da ADI 5581. Existe uma diferença fática relevante entre anencefalia e microcefalia, algo que a diretora da Anis, Diniz (2008, p. 47-52), reconhece: fetos anencéfalos são incapazes de sobreviver após o parto, enquanto crianças com microcefalia sobrevivem na maioria dos casos. Essas crianças também terão deficiências graves, o que gera preocupações quanto a abortos eugênicos.

\section{AS IMPLICAÇÕES DAS RAZÕES DE DECIDIR NA ADPF 54 NOS CASOS DE MICROCEFALIA: ANÁLISE CONCLUSIVA}

Da análise dos votos proferidos quando do julgamento da ADPF 54, notamos que o Supremo Tribunal Federal decidiu, por maioria, pela atipicidade da conduta da mulher que interrompe gravidez de feto anencéfalo, uma vez que não há potencialidade de vida extrauterina. Também se entendeu, na ocasião, que não se deve exigir da mulher o prolongamento inútil da gestação, expondo-a a desnecessário de sofrimento físico e/ou psíquico com grave dano à sua saúde, pois isso viola a sua dignidade, liberdade, autodeterminação, saúde, privacidade e o direito ao pleno reconhecimento dos direitos sexuais e reprodutivos.

Como consignado na ADPF 54, o direito à vida não é absoluto e os direitos do nascituro são condicionados à possibilidade de vida extrauterina viável. Desse modo, o Direito não tutela o feto anencéfalo. Todavia, e o feto acometido pela microcefalia?

Se definimos anencefalia como a má-formação fetal congênita por defeito do fechamento do tubo neural durante a gestação, de modo que o feto não apresenta os hemisférios cerebrais e o córtex, havendo apenas resíduo do tronco encefálico, a microcefalia, segundo a Organização Mundial da Saúde, é uma malformação congênita definida como um tamanho de cabeça muito menor do que a de outros bebês da mesma idade e sexo. A diferença entre as duas doenças está associada à 
viabilidade da vida extrauterina, posto que microcefalia está associada a um crescimento insuficiente do cérebro e os bebês com esta malformação poderão ter problemas de desenvolvimento, mas, diferentemente do caso de anencefalia, poderão ter vida extrauterina.

Devemos aplicas as razões de decidir na ADPF 54 devem se aplicar ao caso de interrupção da gravidez de feto com diagnóstico de microcefalia?

$\mathrm{O}$ argumento da atipicidade da conduta de interrupção da gravidez de feto anencéfalo, tendo em vista a inviabilidade da vida extrauterina, não devemos aceitar no debate sobre o aborto de feto com microcefalia, pois as situações são distintas. Como já afirmamos, no caso da anencefalia, há a inviabilidade da vida extrauterina e, no caso da microcefalia, isso não ocorre.

No entanto, a outra razão de decidir na ADPF 54 trata da impossibilidade de se exigir da mulher o prolongamento da gestação, expondo-a a desnecessário de sofrimento físico e/ou psíquico com grave dano à sua dignidade, liberdade, autodeterminação, saúde, privacidade e ao pleno reconhecimento dos direitos sexuais e reprodutivos. Estes argumentos, na nossa visão, são aptos a fundamentar também a solução do caso da interrupção da gravidez do feto com microcefalia.

Como já reconhecido pelo STF, o direito à vida não é absoluto. E, de fato, o direito à vida do feto, em colisão com direito à vida digna da mulher, bem como o direito à autodeterminação sexual e à autonomia reprodutiva, deve gerar a possibilidade de a mulher grávida escolher não continuar com a gravidez que the causa enorme sofrimento. Só assim estaremos preservando a saúde psíquica da mulher grávida no caso de infecção pelo vírus Zika, colocando-a a salvo de um tratamento desumano, degradante, torturante.

Esta última razão de decidir, adotada na ADPF 54, e que, a nosso ver, se aplica ao caso da interrupção da gravidez no caso de infecção pelo vírus Zika, fica mais robusta com o aprofundamento da análise sobre o direito à liberdade que foi desenvolvida acima. 
Com efeito, a mulher grávida, que se depara com a infecção pelo vírus Zika, que poderá causar grave deformidade no bebê que vier a nascer, deve - como imperativo da dignidade da pessoa humana - ter o direito de escolher, orientando sua vontade sem se condicionar pela vontade dos outros (BOBBIO, 1993, p.100), sendo entendida, assim, como sujeito de direitos e não como objeto da intervenção estatal ou de terceiros (BERLIN, 2002, p. 246-247).

\section{REFERÊNCIAS}

BARROSO, Luís Roberto. A dignidade da pessoa humana no direito constitucional contemporâneo: a construção de um conceito jurídico à luz da jurisprudência mundial. Belo Horizonte: Fórum, 2012.

BARROSO, Luís Roberto. Eficácia e Efetividade do Direito à Liberdade. In: Barroso, Luís Roberto. Temas de Direito Constitucional. Rio de Janeiro: Renovar, 2001.

BEHRMAN, Richard E.; KLIEGMAN, Robert M.; JENSON, Hal B. Tratado de Pediatria. 16. ed. Rio de Janeiro: Guanabara Koogan, 2002.

BERLIN, Isaiah. Dois conceitos de liberdade. In: Estudos sobre a humanidade: uma antologia de ensaios. São Paulo: Companhia das Letras, 2002.

BOBBIO, Norberto. Igualdad y libertad. Barcelona: Paidós, 1993.

BRASIL. STF. ADPF 54, Rel. Min. Marco Aurélio. Julgamento em 12 abr. 2012. DJe de 30 abr. 2013.

COMPARATO, Fábio Konder Comparato. Ética: direito, moral e religião no mundo moderno. São Paulo: Companhia das Letras, 2006.

DIAS, Roberto. O direito fundamental à morte digna: uma visão constitucional da eutanásia. Belo Horizonte: Fórum, 2012.

DINIZ, Debora. Aborto na Suprema Corte: o caso da anencefalia no Brasil. Revista Estudos Feministas, pp. 47-52, 2008. 
FERRAZ, L. Maioria dos brasileiros desaprova aborto mesmo com microcefalia.

Folha de S. Paulo. 29/02/2016. Disponível em <http://www1.folha.uol.com.br/cotidiano/2016/02/1744476-maioria-dos-brasileirosdesaprova-aborto-mesmo-com-microcefalia.shtml.>. Acesso em: 23 jun. 2019.

MAIORIA dos brasileiros segue contrária à legalização do aborto, mostra Datafolha. Folha de S. Paulo. 22/08/2018. Disponível em https://www1.folha.uol.com.br/cotidiano/2018/08/maioria-dos-brasileiros-seguecontraria-a-legalizacao-do-aborto-mostradatafolha.shtml?loggedpaywall?loggedpaywall. Acesso em 23 jun. 2019.

MARTÍNEZ, Gregorio Peces-Barba. Curso de Derecho Fundamentales - Teoria General. Madrid: Coedición Universidade Carlos III de Madrid y Boletín Oficial Del Estado, 1999.

MAXIMILIANO, Carlos. Hermenêutica e Aplicação do Direito. 21. ed. Editora Forense. 2017.

MONTESQUIEU. O espírito das leis. São Paulo: Martins Fontes, 1993.

SARLET, Ingo Wolfgang. O sistema constitucional brasileiro: direitos fundamentais em espécie. In: SARLET, Ingo Wolfgang. MARINONI, Luiz Guilherme; MITIDIERO, Daniel (Org.). Curso de direito constitucional. 3. ed. Rev., atual e ampl. São Paulo: Editora Revista dos Tribunais, 2014.

VENTURA, Miriam. Direitos reprodutivos no Brasil. Brasília: Fundo de População das Nações Unidas, 2009.

VIEIRA, Oscar Vilhena. Direitos fundamentais: uma leitura da jurisprudência do STF. 2. ed. São Paulo: Malheiros, 2017.

Data da submissão: 29/06/2019 Data da primeira avaliação: 13/08/2019 Data da segunda avaliação: 09/08/2019 Data da aprovação: 19/08/2019 